\title{
Análise das Propriedades Físico-Químicas e de Metais Potencialmente Tóxicos na Água do Rio Claro, Próximo \\ a Cidade de Jataí - GO
}

\section{Analysis of Physical-Chemical Properties and Potentially Toxic Metals in Water of the Rio Claro, Next to Jataí City - GO}

\author{
Adriel Martins Lima \\ Instituto de Química de São Carlos \\ Universidade de São Paulo - USP, São Carlos, SP \\ adriel.quimica@gmail.com \\ Francismário Ferreira dos Santos \\ Universidade Federal de Goiás - UFG, Jataí, GO \\ marinhofsantos@hotmail.com
}

Resumo: A agricultura e a pecuária são atividades econômicas indispensáveis na produção de alimentos. Contudo a deposição de resíduos agrícolas e animais têm resultado em alterações ambientais desde a década de 60. Muitas substâncias não degradáveis causam alterações significativas no ecossistema aquático, em especial os metais pesados, elementos cuja densidade excede $5,0 \mathrm{~g} / \mathrm{cm}^{3}$. Uma vez no ambiente, poluem e contaminam as águas, causando diversos problemas em várias formas de vida aquática. Este trabalho teve como objetivo a avaliação do potencial de poluição da água do Rio Claro pelos metais: Bário (Ba), Alumínio ( $\mathrm{Al})$, Ferro $(\mathrm{Fe})$, Cobre (Cu), Chumbo (Pb), Zinco (Zn), Manganês (Mn), Cromo (Cr), Níquel (Ni), Cádmio (Cd), Arsênio (As), Selênio (Se), Mercúrio (Hg) e Cobalto (Co) possivelmente oriundos de atividades agrícolas e a determinação de algumas propriedades físico-químicas ( $\mathrm{pH}$, condutividade, turbidez, dureza, TDS e $\mathrm{NaCl}$ ). As coletas das amostras de água foram feitas em dois períodos do ano (seca e chuva). Todas as análises foram realizadas em acordo com os métodos e padrões oficiais. Os resultados

Recebido em 22/04/2013 - Aceito em 27/05/2013.

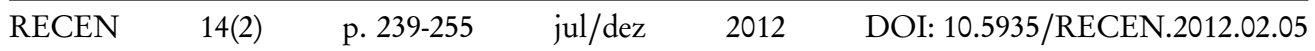


obtidos, relativo aos parâmetros físico-químicos, está dentro do estabelecido pela legislação. A maioria dos metais analisados também está em acordo com a legislação, exceto os metais $\mathrm{Al}, \mathrm{Fe}, \mathrm{Mn}, \mathrm{Cu}$ e $\mathrm{Pb}$.

Palavras-chave: água; contaminação química; metais tóxicos; Rio Claro.

Abstract: The agriculture and the cattle breeding are essential economic activities in food production. However, the depositions of agricultural and animal waste have resulted in environmental changes since the 60s. Many non-degradable substances can cause significant changes in the aquatic ecosystem, especially heavy metals, elements whose density exceeds $5.0 \mathrm{~g} / \mathrm{cm}^{3}$. Once in the environment, contaminate pollute the water, causing various problems in various forms of aquatic life. This study aimed to assess the potential pollution by metals: Barium (Ba), Aluminum (Al), Iron (Fe), Copper (Cu), Lead (Pb), Zinc ( $\mathrm{Zn})$, Manganese (Mn), Chromium $(\mathrm{Cr})$, Nickel (Ni), Cadmium (Cd), Arsenic (As), Selenium (Se), Mercury (Hg) and Cobalt (Co) arising from agricultural activities and some physico-chemical properties $(\mathrm{pH}$, conductivity, turbidity, hardness, and TDS $\mathrm{NaCl}$ ). The water samples were made in two seasons (rainy and dry). All analyzes were performed in accordance with standard methods officers. The results obtained on the physicochemical parameters are within the established by legislation. Most metals are also analyzed in accordance with the law, except the metals $\mathrm{Al}, \mathrm{Fe}, \mathrm{Mn}, \mathrm{Cu}$ and $\mathrm{Pb}$.

Key words: chemical contamination; Rio Claro; toxics metals; water.

\section{Introdução}

Á água é essencial para a sobrevivência de todos no planeta, cada ser humano necessita consumir diariamente vários litros de água potável para manter-se vivo. Contudo a quantidade de água potável no planeta para consumo humano é muito pequena, pois mais de $97 \%$ da água do mundo é constituída de água salgada, indisponíveis para consumo e três quartos da água doce estão presas em geleiras e nas calotas 
polares. Recentemente, foi estimado que a humanidade consome, sobretudo para a agricultura, cerca de um quinto da água que escoa para os mares, e as previsões indicam que essa fração atingirá cerca de três quartos no ano de 2025 [1]. Visto que a água é um recurso renovável, o seu uso pode ser comprometido pela qualidade, que se deteriora em função do grande aporte de resíduos e rejeitos oriundos das atividades antrópicas. É muito difundida a ideia de que os efluentes industriais são os grandes responsáveis pela degradação dos recursos hídricos. Salvo alguns bolsões de alta concentração industrial, a agricultura e a pecuária também contribuem para essa contaminação. Porém o esgoto doméstico ainda é o principal responsável pela situação atual em que se encontram os mananciais brasileiros [2]. Dentre as contaminações presentes nos mananciais brasileiros a contaminação por metal pesado é vista com grande preocupação pelos pesquisadores [3, 4].

A presença de metais pesados, elementos cuja densidade excede $5,0 \mathrm{~g} / \mathrm{cm}^{3}$, e outras substâncias inorgânicas tóxicas são atribuídas aos processos naturais, como o intemperismo das rochas, carreamento de solos e aos processos artificiais, os quais se relacionam aos resíduos das atividades antropogênicas [5]. A diferença entre ambos reside na magnitude do impacto, na frequência (ocasional, contínua ou intermitente) e na duração (horas, meses e anos) em que ocorre a distribuição e contaminação pelos metais, ocasionando impactos consideráveis na estrutura e funcionamento dos ecossistemas. Além disso, deve-se considerar que a contaminação por metais pode ocorrer por fontes difusas, como aquelas originadas pela atmosfera, deposições sólidas e lixiviação do solo, particularmente em áreas agrícolas, e fontes pontuais, caracterizadas principalmente pelas emissões de efluentes industriais, esgotos domésticos, depósitos de lixo e despejos de mineração. Entre os dois processos, os naturais, dependendo de sua magnitude e frequência, são mais assimiláveis pelos ecossistemas, pois ocorrem de forma gradual enquanto os antropogênicos ocorrem em concentrações e duração que não permitem a assimilação pelos ecossistemas, sendo, iguais aos primeiros, cumulativos no sistema. Em relação às fontes, as difusas são mais difíceis de serem controladas [6].

A agricultura e a pecuária são atividades econômicas indispensáveis na produção de alimentos. Contudo tanto a agricultura como a pecuária tem uma necessidade 
imediata de espaço físico, isto faz do desmatamento a primeira consequência prejudicial ao ambiente. Outro problema é o uso indiscriminado de agrotóxicos e de fertilizantes nas lavouras [7]. O Brasil, desde a década de 70, destaca-se como um dos maiores consumidores mundiais de agrotóxicos, principalmente de herbicidas $[8,9]$. Para conseguir suprir as necessidades alimentícias do país o uso de fertilizantes se faz necessário, porém o consumo de fertilizantes no Brasil tem aumentado muito nos últimos anos, passando de 958 mil toneladas, em 1970, para 7,77 milhões de toneladas em 2002, um aumento de $800 \%$ em 3 décadas, segundo a Associação Nacional para Difusão de Adubos - ANDA. Tomando a área com lavouras, o consumo médio de fertilizantes por hectare passou de $18,5 \mathrm{~kg}$ em 1970 para $146 \mathrm{~kg}$ em 2002 [10]. A maioria dos fertilizantes fosfatados, de acordo com a origem, pode conter diversos tipos de metais que podem ser considerados como micronutrientes e metais considerados tóxicos. Esses elementos, quando aplicados no solo, podem persistir por vários anos e rapidamente estar disponíveis para as plantas com potencial risco de acumulação nos solos [11]. O acréscimo na concentração de metais pesados em solos agrícolas, via fertilizantes minerais, pode ser preocupante, devido ao seu potencial risco à saúde humana e ao meio ambiente principalmente nas regiões próximas as lavouras $[12,13]$.

Uma bacia hidrográfica corresponde a uma unidade natural, ou seja, uma determinada área na superfície terrestre, cujos limites são criados naturalmente pelo próprio escoamento das águas ao longo do tempo. Para a determinação de suas propriedades, os tributários de um rio, bem como seu leito, são de fundamental importância. Normalmente, sistemas como um riacho ou um córrego apresentam variações químicas e físicas, entretanto, à medida que seu canal se expande, aumentando o volume de água, a influência de outros cursos confluentes diminui, tornando-se mais estável. Assim, um correto estudo das características fisiográficas da bacia hidrográfica, bem como seu uso e ocupação, torna-se importante fator para a avaliação da degradação ambiental que ela possa estar sofrendo ou mesmo contribuindo para a degradação ambiental de outras bacias [14].

A bacia do Rio Claro possui aproximadamente $13.500 \mathrm{~km}^{2}$, localizada no estado de Goiás, mais precisamente na sua porção sudoeste. É tributária da bacia do 
Paranaíba, com orientação predominante do eixo de drenagem NNW-SSE, paralela às demais sub-bacias do Paranaíba nesse estado. A bacia é composta por dez municípios, nove dos quais possuem parte de suas áreas drenadas pelo Rio Claro, sendo que somente Aparecida do Rio Doce está totalmente inserida nessa bacia. Esses municípios são da microrregião sudoeste de Goiás e Quirinópolis, que fazem parte da mesorregião do Sul Goiano, segundo a classificação do IBGE. Geograficamente, o alto curso da bacia do Rio Claro é limitado pelas coordenadas $51^{\circ} 13^{\prime} 22^{\prime \prime}$ e $52^{\circ} 34^{\prime}$ de longitude Oeste, e $17^{\circ} 01^{\prime} 37^{\prime \prime}$ e $17^{\circ} 58^{\prime} 50^{\prime \prime}$ de latitude Sul [15]. Foi circunscrita a partir das nascentes do Rio Claro e seus afluentes até o córrego Lajeado, na margem esquerda desse rio, a jusante da área urbana de Jataí, cerca de $5 \mathrm{~km}$, sendo que ela foi dividida do restante da bacia hidrográfica considerando-se aspectos práticos, em termos de individualização da área que compreendesse a área urbana de Jataí, a captação de água, o despejo de efluentes urbanos e também pela inserção da estação de monitoramento fluviométrica, que operou basicamente de 1972 a 1988. Considerando apenas o alto curso, o município de Jataí abrange praticamente a metade da área com 47,4\%, Caiapônia ocupa 24,6\%, Perolândia 21,7\% e Mineiros 6,2\%, com área total de $4862,5 \mathrm{~km}^{2}$ [16].

A bacia do Rio Claro é grande produtora de grãos, principalmente milho e soja, começando a se destacar com a expansão da cultura de cana-de-açúcar. Como se sabe, essas culturas demandam a aplicação de elevada quantidade de fertilizantes e agrotóxicos, aliados à grande devastação da mata ciliar, isto acarreta impactos sobre os recursos hídricos das áreas adjacentes a essas plantações, sobretudo através do processo de lixiviação do solo de áreas cultivadas com o uso de tais substâncias. Esse fato pode ser justificado pela alta turbidez e pela entrada de expressiva carga poluidora orgânica para o leito e corpo d'água do Rio Claro [16].

Em relatório desenvolvido pela Agência Goiana do Meio Ambiente (AGMA), relata-se que o Rio Claro recebe efluentes domésticos in natura de várias cidades a partir de seus afluentes. Dentre as cidades, pode-se citar Aparecida do Rio Doce, Caçu, Cachoeira Alta e Jataí, sendo que esta última trata $60 \%$ do efluente e o restante é lançado na forma in natura diretamente no leito do Rio Claro. Esse mesmo relatório menciona ainda que as cidades de Caçu e Jataí utilizam as águas do Rio 
Claro para abastecimento público [17].

A avaliação da qualidade da água tem sido constantemente realizada em inúmeros estudos. Nunes et al. [18] avaliaram a concentração de metais na Bacia do Rio Tibiri, localizada na cidade de São Luís, no Estado do Maranhão, onde apresentou uma alta concentração dos metais chumbo, mercúrio e zinco nas águas do Rio Tibiri, esses provenientes dos resíduos e efluentes do Aterro da Ribeira . Em outro estudo, realizado na bacia do ribeirão Cambé, em Londrina, norte do Paraná, foram encontrados concentrações significativas dos metais $\mathrm{Pb}, \mathrm{Ni}, \mathrm{Cd}, \mathrm{Cr}$ e $\mathrm{Cu}$, esses provenientes da urbanização da região e de atividades industrias. Já os metais $\mathrm{Fe}, \mathrm{Al}$, $\mathrm{Mn}, \mathrm{Ca}$ e Mg são produtos principalmente do carreamento de partículas, através das águas de escoamento [19].

Em razão da possibilidade de introdução de resíduos de agroquímicos e metais potencialmente tóxicos nas águas do Rio Claro, aliado ainda ao fato dela ser utilizada para consumo humano, este trabalho teve como objetivo a avaliação do potencial de contaminação da água do Rio Claro pelos metais: Bário (Ba), Alumínio (Al), Ferro $(\mathrm{Fe})$, Cobre $(\mathrm{Cu})$, Chumbo $(\mathrm{Pb})$, Zinco $(\mathrm{Zn})$, Manganês $(\mathrm{Mn})$, Cromo (Cr), Níquel (Ni), Cádmio (Cd), Arsênio (As), Selênio (Se), Mercúrio (Hg) e Cobalto (Co) possivelmente oriundos de atividades agrícolas e a determinação de algumas propriedades físico-químicas ( $\mathrm{pH}$, condutividade, turbidez, dureza, TDS e $\mathrm{NaCl}$ ). Vale ressaltar, também, que não se encontram trabalhos científicos relativos à presença de metais potencialmente tóxicos nas águas da Bacia do Rio Claro. As informações obtidas neste trabalho permitiram obter uma visão inicial da situação atual da qualidade da água do Rio Claro, e nesse caso, possibilitou identificar as áreas prioritárias a serem acompanhadas em um estudo de monitoramento em longo prazo.

\section{Materiais e métodos}

A coleta das amostras de água do Rio Claro foi realizada em quatros pontos, como indicado na figura 1 . Os frascos para coleta de água foram previamente lavados ao laboratório, em banho com solução de $\mathrm{HNO}_{3}$ diluído e, no local de amostragem, foram lavados três vezes com a água do próprio rio. A extração dos metais 
totais em água seguiu a metodologia descrita pela literatura [20]. Após a coleta de amostras de água adicionou-se $1,5 \mathrm{~mL}$ de $\mathrm{HNO}_{3}$ concentrado. Para extração das amostras de metais em água, reduziu-se um litro de água até o volume aproximado de $100 \mathrm{~mL}$. Durante o processo de concentração adicionou-se $5 \mathrm{~mL}$ de $\mathrm{HNO}_{3}$ concentrado. O material concentrado foi filtrado em filtros de fibra de vidro, GFC, com porosidade de 0,45 $\mu \mathrm{m}$ e colocado em balão de $100 \mathrm{~mL}$. A determinação de metais totais referente às amostras de água coletadas nos meses de setembro de 2009 (período de seca) e as de março de 2010 (período de chuva) foi realizada por espectrometria de emissão atômica com plasma de argônio induzido (ICP-OES), Thermo Jarrel Ash, modelo IRIS/AP.

As análises dos parâmetros físico-químicos como $\mathrm{pH}$, turbidez, condutividade elétrica, $\mathrm{NaCl}$, TDS e temperatura foram realizadas in situ no mesmo período das análises de metais considerando os períodos de chuva e de seca. Foi utilizado o equipamento multiparâmetro, marca Oakton, modelo pH 620. A dureza total foi realizada em laboratório por meio da metodologia descrita pela literatura [20].

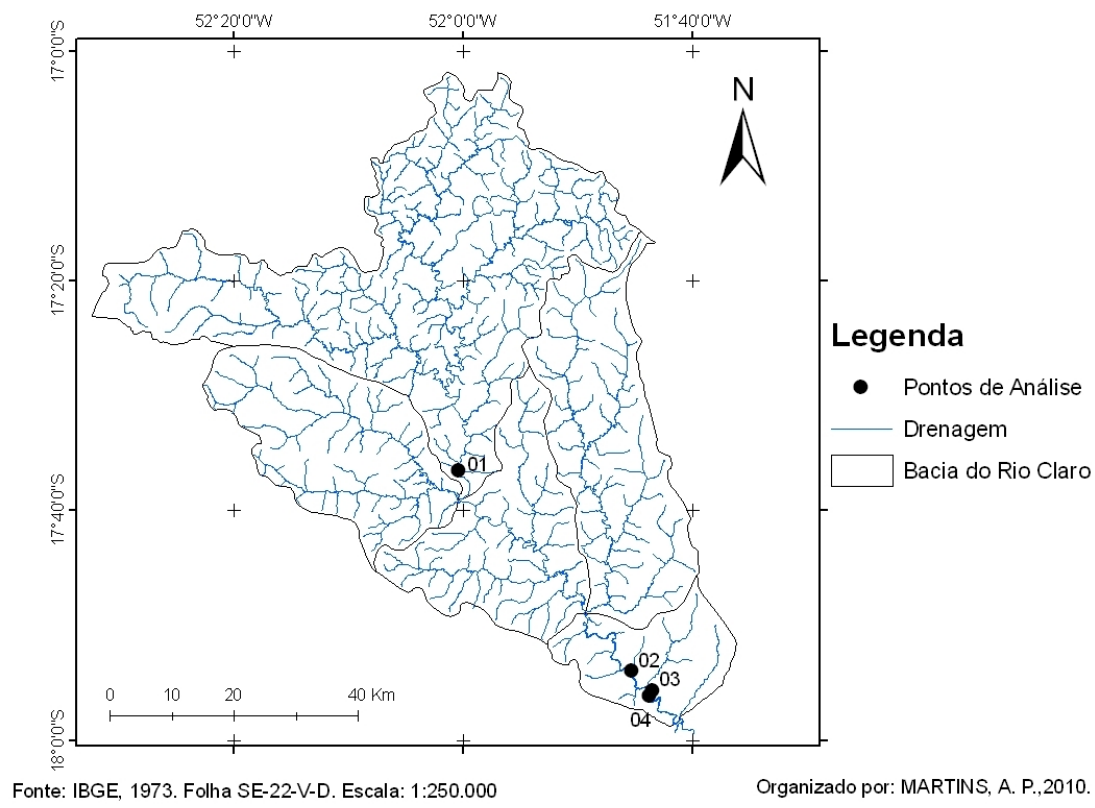

Figura 1. Alto Curso da Bacia do Rio Claro - Localização dos pontos de coleta (P1, P2, P3 e P4) das amostras de água. 


\section{Resultados e discussões}

A localização dos pontos P1 e P2 foram determinadas, levando-se em consideração a intensa atividade agrícola à montante da cidade de Jataí, sendo que o ponto P2 refere-se ao local onde é feita a captação de água para abastecimento público. $\mathrm{O}$ ponto P3 localiza-se à jusante da foz do Córrego Jataí em relação ao Rio Claro. A escolha desse ponto levou em consideração a contribuição da introdução das águas do córrego Jataí, que contém aproximadamente $40 \%$ de esgoto de origem doméstica e industrial da cidade de Jataí. O ponto P4 localiza-se à jusante do ponto P3 e à jusante, também, do ponto de descarte do efluente da estação de tratamento de esgoto da cidade de Jataí. A escolha desses pontos levou em consideração a contribuição do esgoto doméstico e industrial na poluição do Rio Claro. É importante ressaltar que a água do Rio Claro é classificada, de acordo com a resolução CONAMA n. $357 / 2005$, como corpo d'água de classe 2, isto é, água destinada ao abastecimento público, entre outros [21].

A tabela 1 refere-se à média dos resultados dos parâmetros físico-químicos das amostras de água, coletadas nos períodos de chuva e seca.

Tabela 1. Resultado das análises dos parâmetros físico-químicos das amostras de água do Rio Claro, nos períodos de chuva e seca.

\begin{tabular}{ccccccccc}
\hline Coletas & \multicolumn{7}{c}{ Parâmetros Físico-Químicos } \\
\hline & & $\mathrm{pH}$ & $\begin{array}{c}\text { Cond. } \\
(\mu \mathrm{S})\end{array}$ & $\begin{array}{c}\text { Turbidez } \\
(\mathbf{N T U})\end{array}$ & $\begin{array}{c}\text { Dureza(mg } \\
\left.\mathrm{CaCO}_{3} / \mathrm{L}\right)\end{array}$ & $\begin{array}{c}\mathrm{NaCl} \\
(\mathrm{ppm})\end{array}$ & $\begin{array}{c}\text { TDS* } \\
(\mathrm{ppm})\end{array}$ & $\begin{array}{c}\text { Temp. } \\
\left({ }^{\circ} \mathrm{C}\right)\end{array}$ \\
\hline $\begin{array}{c}\text { (Período } \\
\text { de Chuva) }\end{array}$ & $\mathrm{P} 1$ & 7,21 & 29,4 & 53,2 & 17,9 & 21,3 & 15,6 & 24,7 \\
& $\mathrm{P} 2$ & 6,78 & 24,1 & 94,3 & 15,9 & 19,1 & 12,8 & 25 \\
& $\mathrm{P} 3$ & 6,64 & 26,1 & 82,3 & 7,97 & 20,3 & 14,6 & 25,8 \\
& $\mathrm{P} 4$ & 6,62 & 26,7 & 84 & 12 & 20,7 & 15,3 & 26,8 \\
(Período & & & & & & & & \\
de Seca) & P1 & 6,34 & 31,9 & 14,2 & 37,9 & 37,2 & 33,1 & 22,6 \\
& P2 & 6,43 & 33,2 & 34,5 & 39,8 & 21,4 & 15,7 & 22,9 \\
& P3 & 6,6 & 39,3 & 23,5 & 23,9 & 24,1 & 18,6 & 23,3 \\
& P4 & 6,48 & 43,5 & 23,4 & 27,9 & 25,6 & 20,4 & 23,2 \\
\hline
\end{tabular}

*Total de sólidos Dissolvidos

Em águas naturais, as variações de $\mathrm{pH}$ são ocasionadas geralmente pelo con- 
sumo e/ou produção de dióxido de carbono $\left(\mathrm{CO}_{2}\right)$, realizados pelos organismos fotossintetizadores e pelos fenômenos de respiração ou fermentação de todos os organismos presentes na água, produzindo ácidos orgânicos fracos [1]. A resolução CONAMA n.357/2005 determina que as águas destinadas ao abastecimento e ao consumo humano devem conter seu $\mathrm{pH}$ na escala de 6,0 a 9,0. De acordo com os resultados, tabela 1 , o $\mathrm{pH}$ das amostras de água no período de chuva para ambos os pontos estão em conformidade com a legislação brasileira. $\mathrm{O}$ mesmo foi verificado em todos os pontos para o período de seca.

A condutividade elétrica da água é uma medida da sua capacidade em conduzir corrente elétrica, sendo proporcional à concentração de íons dissociados em um sistema aquático. Esse parâmetro não permite identificar a espécie química responsável pela alteração, no entanto, fornece um indicativo real da poluição ou possível fonte de poluição [21]. É importante ressaltar que esse parâmetro é válido para águas de rios, lagos, represas, etc, não devendo ser considerado para mares, oceanos e água mineral. A alta condutividade para águas superficiais deve-se à presença de inúmeras espécies, por exemplo: sabão, detergentes e águas de lavagem contendo elevada quantidade de matéria orgânica, que contribuem para a entrada, no corpo d'água, de espécies iônicas como cálcio, magnésio, potássio, sódio, fosfatos, carbonatos, sulfatos, cloretos, nitratos, nitritos e amônia, dentre outras [22]. Quanto maior a quantidade de íons, maior é a condutividade. De acordo com a tabela 1 , no período de chuva, os valores de condutividade variaram de $24,1 \mu \mathrm{S} / \mathrm{cm}$ a 29,4 $\mu \mathrm{S} / \mathrm{cm}$ e no período de seca de $31,9 \mu \mathrm{S} / \mathrm{cm}$ a $43,5 \mu \mathrm{S} / \mathrm{cm}$. O aumento observado no período de seca pode estar relacionado à diminuição do volume de água. Já, no período de seca, foi observado um ligeiro aumento do valor da condutividade nos pontos $\mathrm{P} 3(39,3 \mu \mathrm{S} / \mathrm{cm})$ e $\mathrm{P} 4(43,5 \mu \mathrm{S} / \mathrm{cm})$. Esse aumento pode ser atribuído à contribuição de íons presentes na composição do Córrego Jataí e do efluente da estação de tratamento de esgoto da cidade de Jataí, respectivamente.

A turbidez é medida pela quantidade de luz refletida pela água de uma amostra. É um parâmetro adotado nas atividades de controle de poluição da água e de verificação do parâmetro físico nas águas consideradas potáveis. Observando a tabela 1, os valores no período de chuva variaram de 53,4 NTU (P1) a 94,3 NTU 
(P2), e no período de seca houve a variação de 14,2 NTU (P1) a 34,5 NTU (P2). Embora tenha sido observado ligeiro aumento na turbidez do P1 para o P2 em ambos os períodos, os valores encontram-se dentro da faixa permitida pela resolução CONAMA n. 357/2005 que é permitido turbidez de até 100 NTU.

A dureza da água é a soma das concentrações de íons divalentes, principalmente $\mathrm{Ca}^{2+}$ e $\mathrm{Mg}^{2+}$, sendo expressa em miligramas por litro de carbonato de cálcio. O cálcio e magnésio estão presentes na água, principalmente nas formas de bicarbonatos de cálcio e de magnésio, sulfatos de cálcio e de magnésio [1]. De acordo com a literatura, o consumo de águas com dureza elevada confere sabor desagradável e efeito laxativo [23]. Através dos valores de dureza obtidos (tabela 1), pode-se perceber que, no período de chuva, ocorreu uma variação de 7,97 a 19,90 mg/L de $\mathrm{CaCO}_{3}$ e, no período de seca, ocorreu variação de 23,9 a 27,9 mg/L de $\mathrm{CaCO}_{3}$. O aumento verificado no período de seca pode ser atribuído à diminuição do volume de água nesse período e com isso há um aumento da concentração dos íons cálcio e magnésio. Com relação aos pontos $\mathrm{P} 1$ e P2, em ambos os períodos de coleta, os resultados de dureza revelaram ligeiramente maiores que os determinados para os pontos P3 e P4. Esse fato pode ser atribuído em função da intensa atividade agrícola na região entre esses pontos (P1 e P2). Deve ser lembrado que o solo da região em estudo é tipicamente ácido e, por esse motivo, há a necessidade da correção do $\mathrm{pH}$ do solo por meio da adição de calcário, contribuindo assim, com o aumento na concentração de íons $\mathrm{Ca}^{2+}$ nas águas do Rio Claro, por meio do processo de lixiviação. Os valores determinados classificam a água do Rio Claro como água mole, que são águas com dureza abaixo de $50 \mathrm{mg} / \mathrm{L}$ [24].

Os valores relativos à salinidade e TDS encontram-se em conformidade com a condutividade, ou seja, o aumento na concentração de íons em solução reflete em aumento da condutividade.

A temperatura manteve-se em torno de $22,6^{\circ} \mathrm{C}$ a $26,8^{\circ} \mathrm{C}$ considerando os dois períodos de coleta, foi verificado um discreto aumento nos pontos P3 e P4. Isso pode ser justificado em função do horário, sendo, que nesses pontos, as amostras foram coletadas no período da tarde, em que a incidência da radiação solar é maior.

As tabelas 2 e 3 referem-se às médias dos resultados das análises de metais em 
amostras de água superficial, nos períodos de chuva e seca respectivamente. Os resultados das análises de metais totais, referente ao período de chuva, tabela 2 , revelaram a presença dos metais $\mathrm{Ba}, \mathrm{Al}, \mathrm{Fe}, \mathrm{Cu}, \mathrm{Pb}, \mathrm{Zn}, \mathrm{Mn}, \mathrm{Cr}, \mathrm{Ni}, \mathrm{Cd}$ e Co enquanto os metais $\mathrm{Hg}$, Se e As, não foram detectados em nenhuma das amostras. Embora se tenha observado a presença dos metais em todas as amostras, somente os metais Al, $\mathrm{Fe}, \mathrm{Mn}$ e $\mathrm{Pb}$ foram encontrados em concentração acima do valor permitido pela resolução CONAMA n. 357/2005 que é de 0,1; 0,3; 0,1 e 0,01 mg/L respectivamente para $\mathrm{Al}, \mathrm{Fe}, \mathrm{Mn}$ e $\mathrm{Pb}$ [25]. A presença dos metais $\mathrm{Al}$ e $\mathrm{Fe}$, em concentração acima do valor permitido pela legislação brasileira, pode ser atribuída ao carreamento de partículas do solo contendo esses metais aderidos em sua superfície. Como descrito anteriormente, o solo da região é rico nesses metais.

Tabela 2. Concentração $(\mathrm{mg} / \mathrm{L})$ de metais totais em amostra de água superficial do Rio Claro, obtidos por espectrometria de emissão atômica com plasma de argônio induzido (ICP-OES).

\begin{tabular}{ccccc}
\hline \multicolumn{5}{c}{ Concentração de metais totais (mg/L) } \\
\hline Metais & P1 & P2 & P3 & P4 \\
\hline Ba & $0,0194 \pm 0,0013$ & $0,0170 \pm 0,0013$ & $0,0174 \pm 0,0013$ & $0,0158 \pm 0,0013$ \\
$\mathbf{A l}$ & $0,2988 \pm 0,0149$ & $0,1712 \pm 0,0126$ & $0,3086 \pm 0,0154$ & $0,2318 \pm 0,0114$ \\
$\mathbf{F e}$ & $0,325 \pm 0,0161$ & $0,1596 \pm 0,0119$ & $0,2998 \pm 0,0149$ & $0,2422 \pm 0,0120$ \\
$\mathbf{C u}$ & $0,0184 \pm 0,0023$ & $0,0174 \pm 0,0026$ & $0,0216 \pm 0,0027$ & $0,0214 \pm 0,0027$ \\
$\mathbf{P b}$ & $0,0360 \pm 0,0006$ & $0,0108 \pm 0,0006$ & $0,0180 \pm 0,0006$ & $0,0328 \pm 0,0007$ \\
$\mathbf{Z n}$ & $0,0178 \pm 0,0062$ & $0,0186 \pm 0,0062$ & $0,0212 \pm 0,0062$ & $0,0286 \pm 0,0062$ \\
$\mathbf{M n}$ & $0,0206 \pm 0,0025$ & $0,0138 \pm 0,0025$ & $0,0074 \pm 0,0025$ & $0,0088 \pm 0,0025$ \\
$\mathbf{C r}$ & $0,0074 \pm 0,0025$ & $0,0088 \pm 0,0026$ & $0,0174 \pm 0,0026$ & $0,0074 \pm 0,0025$ \\
$\mathbf{N i}$ & $0,0038 \pm 0,0025$ & $0,0036 \pm 0,0025$ & $0,006 \pm 0,0025$ & $0,008 \pm 0,0025$ \\
$\mathbf{C d}$ & $\mathrm{ND}$ & $\mathrm{ND}$ & $\mathrm{ND}$ & $\mathrm{ND}$ \\
$\mathbf{A s}$ & $\mathrm{ND}$ & $\mathrm{ND}$ & $\mathrm{ND}$ & $\mathrm{ND}$ \\
$\mathbf{S e}$ & $\mathrm{ND}$ & $\mathrm{ND}$ & $\mathrm{ND}$ & $\mathrm{ND}$ \\
$\mathbf{H g}$ & $\mathrm{ND}$ & $\mathrm{ND}$ & $\mathrm{ND}$ & $\mathrm{ND}$ \\
$\mathbf{C o}$ & $\mathrm{ND}$ & $\mathrm{ND}$ & $\mathrm{ND}$ & $\mathrm{ND}$ \\
\hline
\end{tabular}

ND: Não detectado

A tabela 3 apresenta os resultados das análises de metais totais, referente ao período de seca. 
Revista Ciências Exatas e Naturais, Vol.14, n², Jul/Dez 2012

Tabela 3. Concentração $(\mathrm{mg} / \mathrm{L})$ de metais totais em amostra de água superficial do Rio Claro, obtidos por espectrometria de emissão atômica com plasma de argônio induzido (ICP-OES).

\begin{tabular}{ccccc}
\hline \multicolumn{5}{c}{ Concentração de metais totais (mg/L) } \\
\hline Metais & Período de Seca \\
\hline & $\mathbf{P 1}$ & P2 & P3 & P4 \\
\hline $\mathbf{B a}$ & $0,0344 \pm 0,0013$ & $0,1169 \pm 0,0014$ & $0,1187 \pm 0,0015$ & $0,0799 \pm 0,0014$ \\
$\mathrm{Al}$ & $3,995 \pm 0,0307$ & $21,3100 \pm 0,1480$ & $21,8900 \pm 0,1958$ & $11,6600 \pm 0,0839$ \\
$\mathrm{Fe}$ & $2,7250 \pm 0,0261$ & $12,1600 \pm 0,0819$ & $12,0400 \pm 0,0814$ & $7,1820 \pm 0,0419$ \\
$\mathrm{Cu}$ & $0,0177 \pm 0,0026$ & $0,0420 \pm 0,0021$ & $0,0366 \pm 0,0027$ & $0,0187 \pm 0,0023$ \\
$\mathrm{~Pb}$ & $0,0049 \pm 0,0006$ & $0,0096 \pm 0,0006$ & $0,0098 \pm 0,0006$ & $0,0068 \pm 0,0006$ \\
$\mathrm{Zn}$ & $0,0390 \pm 0,0062$ & $0,0302 \pm 0,0062$ & $0,0326 \pm 0,0062$ & $0,0195 \pm 0,0062$ \\
$\mathrm{Mn}$ & $0,0375 \pm 0,0025$ & $0,2058 \pm 0,0031$ & $0,1761 \pm 0,0026$ & $0,1906 \pm 0,0028$ \\
$\mathrm{Cr}$ & $0,0075 \pm 0,0005$ & $0,0284 \pm 0,0028$ & $0,0224 \pm 0,0025$ & $0,0147 \pm 0,0026$ \\
$\mathbf{N i}$ & $0,0036 \pm 0,0005$ & $0,0106 \pm 0,0005$ & $0,0099 \pm 0,0005$ & $0,0064 \pm 0,0005$ \\
$\mathrm{Cd}$ & $\mathrm{ND}$ & $\mathrm{ND}$ & $\mathrm{ND}$ & $\mathrm{ND}$ \\
$\mathrm{As}$ & $0,0004 \pm 0,0006$ & $0,0013 \pm 0,0006$ & $0,0014 \pm 0,0006$ & $0,0012 \pm 0,0006$ \\
$\mathrm{Se}$ & $\mathrm{ND}$ & $\mathrm{ND}$ & $\mathrm{ND}$ & $\mathrm{ND}$ \\
$\mathrm{Hg}$ & $\mathrm{ND}$ & $\mathrm{ND}$ & $\mathrm{ND}$ & $\mathrm{ND}$ \\
$\mathrm{Co}$ & $0,0006 \pm 0,0005$ & $0,0059 \pm 0,0005$ & $0,0044 \pm 0,0005$ & $0,0028 \pm 0,0005$ \\
\hline
\end{tabular}

ND: Não detectado

Os mesmos metais encontrados no período chuva, ou seja, os metais $\mathrm{Ba}, \mathrm{Al}$, $\mathrm{Fe}, \mathrm{Cu}, \mathrm{Pb}, \mathrm{Zn}, \mathrm{Mn}, \mathrm{Cr}, \mathrm{Ni}, \mathrm{Cd}$ e Co foram detectados nas amostras coletadas no período de seca, exceto os metais $\mathrm{Cd}, \mathrm{Hg}$ e Se. Com relação aos valores permitidos pela legislação CONAMA n.357/2005, os metais Al, Fe, Cu e Mn encontram-se em concentração acima do valor permitido. Comparando-se o ponto P2 com relação aos demais pontos de coleta (P1, P3 e P4), pode-se notar uma maior concentração dos metais analisados, especialmente os metais que estão em concentração acima do permitido. Como relatado anteriormente, o ponto P2 refere-se ao ponto de captação de água para abastecimento público da cidade de Jataí, fato de grande preocupação futura para a população local. A figura 1 mostra a contribuição de inúmeros tributários de água do Rio Claro, que podem contribuir para o escoamento de agroquímicos e fertilizantes, contendo os metais estudados. Tal fato pode justificar a alta concentração de $\mathrm{Al}, \mathrm{Fe}, \mathrm{Cu}$ e $\mathrm{Mn}$ nas amostras de água nos pontos P2, P3 e P4, pontos equidistantes de P1 de aproximadamente $45 \mathrm{~km}$. É importante relatar 
que a produção agrícola é muito expressiva nesse trecho e que há grande destruição da mata ciliar próxima às margens do Rio Claro. Esses fatos também podem facilitar o carreamento de resíduos agrícolas diretamente no leito do Rio Claro e, consequentemente, aumentar as concentrações dos metais. Os pontos P3 e P4, embora recebendo a contribuição das águas do Córrego Jataí e do efluente da estação de tratamento de esgoto doméstico e industrial da cidade de Jataí, não revelaram a presença de quantidade excessiva dos outros metais estudados.

Considerando os meses de coleta das amostras, pode-se dizer que o aumento significativo na concentração dos metais ocorreu no período de seca, período em que o volume de água é reduzido e, consequentemente, a concentração dos metais é aumentada.

Todos os valores encontrados foram determinados levando-se em consideração os limites de detecção (LD) e de quantificação (LQ) do equipamento para cada metal. Já os desvios encontrados foram calculados considerando-se a faixa de $95 \%$ de confiança $[26,27]$.

Embora as concentrações dos metais $\mathrm{Cd}, \mathrm{Cr}, \mathrm{Zn}, \mathrm{As}, \mathrm{Pb}$, e $\mathrm{Zn}$ não estejam acima dos valores permitidos, tais metais poderão ser um problema futuro para a região em estudo, pois podem estar presentes como impurezas nas formulações de insumos agrícolas $[28,29]$.

\section{Conclusões}

Os resultados das análises revelaram a presença dos seguintes metais pesados nas amostras de água: $\mathrm{Cd}, \mathrm{Cr}, \mathrm{Zn}, \mathrm{As}, \mathrm{Pb}$, e $\mathrm{Zn}$. Os metais $\mathrm{Al}, \mathrm{Fe}, \mathrm{Cu}$ e $\mathrm{Mn}$ encontram-se em concentração acima do permitido pela legislação CONAMA n. 357/2005. A presença dos metais nas amostras analisadas pode ser atribuída, em função da atividade agrícola com a devastação da mata ciliar do trecho em estudo e da lixiviação natural do solo predominantemente ácido da região. É necessário um monitoramento contínuo das águas do Rio Claro, uma vez que a cidade de Jataí e Caçu o utilizam como fonte de captação de água para consumo humano. Para uma maior avaliação do potencial de contaminação das águas do Rio Claro por metais pesados, sugere-se que se façam análises do sedimento, pois este é um importante 
Revista Ciências Exatas e Naturais, Vol.14, n², Jul/Dez 2012

indicador ambiental.

\section{Referências}

[1] BAIRD, C. Química Ambiental. 2ª edição. Porto Alegre: Bookman, 2002.

[2] LEMES, M. J. L. Avaliação de metais e elementos-traço em águas e sedimentos das bacias hidrográficas dos Rios Mogi-Guaçu e Pardo. Dissertação de Mestrado, Instituto de Pesquisas Energéticas e Nucleares, Universidade de São Paulo, São Paulo, 2001.

[3] NASCIMENTO, R. S. M. P.; CARVALHO, G. S.; PASSOS, L. P.; MARQUES, J. J. Lixiviação de chumbo e zinco em solo tratado com resíduos de siderurgia. Pesq Agropecu Tropical, v.40, n.4, p.497-504, 2010.

[4] RIBEIRO, E. V.; MAGALHÃES-JUNIOR, A. P.; HORN, A. H.; TRINDADE, W. M. Metais pesados e qualidade da água do Rio São Francisco no segmento entre Três Marias e Pirapora - MG: Índice de contaminação. Geonomos, v.20, n. 1, p.49-63, 2012.

[5] COTTA, J. A. O.; REZENDE, M. O. O.; PIOvANI, M. R. Avaliação do teor de metais em sedimento do rio Betari no Parque Estadual Turístico do Alto Ribeira - PETAR, São Paulo, Brasil. Quim Nova, v.29, n.1, p.40-45, 2006.

[6] CALMANO, W. Metals in sediments: Remobilization and environment hazards. In: MUNAWAR, M ; DAVE, G., eds. Development and Progress in Sediment Quality Assessment: Rationale, Challenges, Techiques \& Strategies, p.113, 1996.

[7] CARVALHO, A. R.; SCHILITTLER, F. H. M.; TORNISIELO, V. L. Relações da atividade agropecuária com parâmetros físicos químicos da água. Quim Nova, v.23, v.5, p.618-622, 2000.

[8] PRIMEL, E. G.; ZANELLA, R.; KURZ, M. H. S.; GONÇALVES, F. F.; MACHADO, S. O.; MARCHEZAN, E. Poluição das águas por herbicidas utilizados no cultivo do arroz irrigado na região central do estado do Rio Grande do 
Sul, Brasil: predição teórica e monitoramento. Quim Nova, v.28 n.4, p.605-609, 2005.

[9] BESSEGATO, G. G.; SANTOS, V. P.; LINDINO, C. A. Degradação fotoeletroquímica do herbicida bentazona sobre eletrodos de carbono modificados por $\mathrm{TiO}_{2}$. Quim Nova, v.35, n.2, p.332-336, 2012.

[10] NEVES, E.M.; RODRIGUES, L.; DAYOUB, M.; DRAGONE, D. S. Fertilizantes no plano real: estratégias empresariais e demanda. Relatório de pesquisa. Escola Superior de Agricultura Luiz de Queiroz, Universidade de São Paulo, Piracicaba, 2002.

[11] CARNELO, L. G. L.; MIGUEZ, S. R.; MARBÁN L. Heavy metals input with phosphate fertilizers used in Argentina. Sci Total Environment, v.204, n.3, p.245-250, 1997.

[12] LAMBERT, R.; GRANT C; SAUVÉ S. Cadmium and zinc in soil solution extracts following the application of phosphate fertilizers. Sci Total Environment, v.378, n.3, p.293-305, 2007.

[13] NZIGUHEBA, G.; SMOLDERS, E. Inputs of trace elements in agricultural soils via phosphate fertilizers in European countries. Sci Total Environment, v.390, n.1, p.53-57, 2008.

[14] MARGALEF, R. Limnologia. Barcelona, Omega, 1983. $\mathrm{CBH}$ - PARANAÍBA. Disponível em http://www.paranaiba.cbh.gov.br/_docs/outros/Texto_para_o_site_Concurso_Foto.pdf. Acesso em Jun/2013.

[16] MORAGAS, W.M. Análise dos sistemas ambientais do alto Rio Claro - Sudoeste de Goiás: subsídios ao planejamento e gestão. Tese de Doutorado, Universidade Estadual Paulista, Instituto de Geociências e Ciências Exatas, UNESP, Rio Claro, 2005. 
Revista Ciências Exatas e Naturais, Vol.14, n², Jul/Dez 2012

[17] GOIÁS. AGMA -Agência Goiana do Meio Ambiente. Estudo integrado de bacias hidrográficas do sudoeste de Goiás. Relatório final, 2004.

[18] CAMPOS, A. E. L.; NUNES, G. S.; OLIVEIRA, J. C. S.; TOSCANO, I. A. S. Avaliação da contaminação do Igarapé do Sabino (Bacia do Rio Tibiri) por metais pesados, originados dos resíduos e efluentes do Aterro da Ribeira, em São Luís, Maranhão. Quim Nova, v.32, n.4, p.960-964, 2009.

[19] YABE, M. J. S.; OLIVEIRA, E. Metais pesados em águas superficiais como estratégia de caracterização de bacias hidrográficas. Quim Nova, v.21, n.5, p.551556, 1998.

[20] American Public Health Association. Standard Methods for examination water and wastewater. 14th Ed. New York, 1995.

[21] BRASIL. Conselho Nacional do Meio Ambiente; Resolução CONAMA n ${ }^{0}$. 357, de 17 de março de 2005, Brasília, 2005.

[22] ZUIN, V.G.; IORIATTI, M. C. S.; MATHEUS, C. E. O O emprego de parâmetros físicos e químicos para a avaliação da qualidade de águas naturais: Uma proposta para a educação química e ambiental na perspectiva CTSA. Cadernos Temáticos de Química Nova na Escola, v.31, n.1, 2009.

[23] GUIMARÃES, J. R.; NOUR, E. A. A. Tratando nossos esgotos: Processos que imitam a natureza. Cadernos Temáticos de Química Nova na Escola - Química Ambiental, 2001.

[24] VON SPERLING, M. Introdução à qualidade das águas e ao tratamento de esgotos. Belo Horizonte: Departamento de Engenharia Sanitária e Ambiental, UFMG, 1995.

[25] Ministério da Saúde - Vigilância e controle da qualidade da água para consumo humano. Disponível em http://bvsms.saude.gov.br/bvs/publicacoes/vigilancia_controle_qualidade_ agua.pdf. Acesso em Jun/2013. 
[26] LEITE, F. Validação em análise química. 40 ed., Campinas, Editora Átomo, 2002.

[27] SKOOG, D. A.; WEST, D. M.; HOLLER, F. J.; CROUCH, S. R. Fundamentos de química analítica. Tradução de Marco Tadeu Grassi e Celio Pasquini. São Paulo, Editora Thomson, 2006.

[28] PROCHNOW, T. R.; PROCHNOW, E. A.; LIBERMAN, B. Efeitos antrópicos sobre concentrações de metais alcalinos na região da microbacia do Arroio Araçá, Canoas, Rio Grande do Sul. Quim Nova, v.32, n.7, p.1782-1786, 2009.

[29] PAUlA, F. C. F.; LACERDA, L. D.; MARINS, R. V.; AGUIAR, J. E.; OVALlE, A. R. C.; FALCÃO-FILHO, C. A. T. Emissões naturais e antrópicas de metais e nutrientes para a bacia inferior do Rio de Contas, Bahia. Quim Nova, v.33, n.1, p.70-75, 2010. 